\title{
Immature Adults and Playing Children: On Bernard Stiegler's Critique of Infantilization
}

\author{
Daan Keij ${ }^{1}$ (D) \\ Accepted: 10 October 2020 / Published online: 16 October 2020 \\ (c) The Author(s) 2020
}

\begin{abstract}
This article assesses Bernard Stiegler's critique of infantilization. Contemporary education-and society in general-would no longer develop children into adults, but would keep them in their childish state. Stiegler's critique is explicitly inspired by Enlightenment ideals, characterized by a positive notion of maturity and a negative notion of childhood and immaturity. Infantilization is for Stiegler therefore immediately a negative development. However, Stiegler's works also contain a positive understanding of childhood and of the extension of childish characteristics into adulthood. The main thesis of this article is that this results in an unresolved tension in Stiegler's work. I therefore propose a notion of infantilization not as solely negative, but as fundamentally ambivalent and risky. The continuation of childhood into maturity is necessary for the life of the mind, yet it can also foreclose maturity altogether. I use this new notion of infantilization to correct some of Stiegler's radically conservative views on education and on the care for the new generations.
\end{abstract}

Keywords Infantilization $\cdot$ Childhood $\cdot$ Stiegler $\cdot$ Maturity $\cdot$ Playing $\cdot$ Enlightenment

\section{Introduction}

The work of French philosopher Bernard Stiegler is increasingly taken up in philosophy of education. This is attested by two recent issues focusing solely on his work: the May 2016 issue of this journal and a 2020 issue of Educational Philosophy and Theory. Stiegler's attention to the intrinsic relation between mind and technology and the contemporary shifting technological context resonates with problems education is facing today. In this article I will not elaborate on this in much detail, as the merits of Stiegler's work for education have already been elaborated in other works. ${ }^{1}$ Rather, I will focus on a tension

\footnotetext{
1 See Bradley and Kennedy (2020) for an overview of Stiegler's contributions to the philosophy of education.
}

Daan Keij

d.keij@ubn.ru.nl

1 Tilburg, The Netherlands 
in Stiegler's critique of what he terms infantilization: the cultural regression of adulthood towards immaturity $(2010 ; 2015,1-41)$. Contemporary education-and society in general-would no longer develop children into adults, but would keep them in their childish state. ${ }^{2}$ Although Stiegler's work has led to a wide range of commentaries and developments by both proponents and opponents, his critique of infantilization has not yet been explicitly commented upon. The same goes for similar notions such as minoritization or regression (2010, 2013b, 7-56, 2015, 1-41, 2018).

I specifically focus on these terms, and not on other notions which Stiegler uses roughly interchangeably with them, such as stupidity (Stiegler 2015). This is because infancy, minority and regression, contrary to stupidity, all refer implicitly to a state of childhood. The aim of this article is to study Stiegler's understanding of childhood in connection with his critique of infantilization, and ultimately, to correct the tension that this reveals. The literature does not yet contain a study of the possibility of such a synthesis, even though the different aspects of it have been studied separately.

In the May 2016 issue of this journal focused on Stiegler's work, some contributors mention the term infantilization, but only consider Stiegler's explication of it and not the reference to infancy it entails (for example Lewin 2016). The same goes for the recent issue of Educational Philosophy and Theory (2020) which also focuses specifically on Stiegler. Although contributors address Stiegler's warning for our times (Forrest 2020; Bradley 2020), they do so without focusing on the terminology of infantilization, minoritization or regression. And in the interesting exploration of a Stieglerian philosophy of infancy (Kouppanou 2020), no mention is made of the negative connotations infancy receives in Stiegler's critique of infantilization.

The primary goal of my investigation is to test the consistency of Stiegler's critique. This serves three main purposes. First, it fills a lacuna in the commentary on Stiegler's work. Second, it clarifies a tension inherent in a critique of infantilization in general, since Stiegler's argument can serve as an example for other similar critiques. ${ }^{3}$ Third and most importantly, it reveals how a one-sided critique of infantilization leads to one-sided views on education.

My main argument is structured as follows: in the first section I present the notion of infantilization, mainly by means of Stiegler's reception of Kant's What is Enlightenment?. As we will see, Stiegler takes up the main characteristics of Kant's interpretation of immaturity and maturity. This interpretation is characterized by a negative understanding of childhood — childhood as lack of maturity — and therefore a negative conception of infantilization. In the second section, I present in more detail the differences in Kant and Stiegler, to bring out how Stiegler actualizes the Kantian message for our times. The third section prepares for a correction of Stiegler's notion of infantilization by means of an analysis of some of Stiegler's other remarks on childhood. This reveals an understanding that is at odds with his 'Enlightenment understanding.' Rather than solely a negation of maturity,

\footnotetext{
${ }^{2}$ In the context of education, this is also argued by Frank Furedi in Wasted (2009) and already in the Dutch pedagogical classic Grootbrengen door kleinhouden by Lea Dasberg (1975).

3 Benjamin Barber's influential tome on infantilization arguably follows a similar line as Stiegler's work. Barber begins by vehemently criticizing infantilization, but ends his book by discussing some virtues of childhood we should not give up. To enhance the confusion, Barber even considers a kind of childish practice - the playfulness of the Situationists - as a possible solution to the dangers of our times (2007). Other examples of similar critiques can be found in the works of contemporary thinkers Dany-Robert Dufour (2008) and Alain Badiou (2017). In all these examples, the notion of infantilization can be critically augmented in similar ways as I do in this article.
} 
Stiegler also considers childhood the age of play and affirms the necessity of continuing it throughout maturity for the life of the mind. I therefore propose to include these aspects of childhood in the notion of infantilization as well. This leads to a different understanding of infantilization not as solely negative, but as fundamentally ambivalent and risky. I briefly summarize the consequences of this new notion for Stiegler's views on education and taking care of new generations, while also noting some directions for future research.

\section{The Critique of Infantilization: History and Kantian Inspiration}

I will start my analysis with a short history of the notion of infantilization. ${ }^{4}$ Now to be precise, the critique of infantilization is not new. In the nineteenth century, critics already complained of infantilization in the works of Romantic poets such as William Wordsworth (Rowland 2012, 1-3). But even well before that, in ancient Greece, we can find similar accusations. In Plato's Gorgias, Callicles complains of older men who continue with childish practices. He says: "But when one hears a man speaking haltingly or sees him playing like a child, it strikes me as ridiculous and unmanly, deserving of a flogging" (Plato 1997, 829). Such childish practices also include philosophizing: "When I see philosophy in a young boy, I approve of it... But when I see an older man still engaging in philosophy and not giving it up, I think such a man by this time needs a flogging" (ibid.).

However, it is only in the previous century that the idea emerges that not just certain individuals can fall prey to infantilization, but entire cultures as well. In 1944, antropologist Claude Levi-Strauss undertook a cultural analysis of the United States and concluded that behaviour and preferences previously characteristic of childhood persevered more and more in adulthood as well (1946, 647; see also Gottschalk 2018). Postman's 1982 book The Disappearance of Childhood deserves specific mention, as Postman, like Stiegler, explicitly relates developments in the notions of childhood and adulthood with technological developments. In the last decade, the complaint of infantilization not only resounded widely in academic works, but in popular magazines, blogs and books as well (Barber 2007; Gottschalk 2018; Pfeiffer 2018).

Interestingly, the critique of infantilization appears on both sides of the political spectrum. The right-wing blog The Imaginative Conservative, for example, contains multiple contributions criticizing today's supposed infantile culture, but the same criticism also appears in the works of leftist thinkers such as Félix Guattari (2009) and Mark Fisher (2009). Therefore, it is not simply a matter of conservatives with a disdain for youth's promises of new possibilities, versus progressives seeking to clear as much space as possible for this youthful potential. The problem of infantilization is more complex.

This complexity immediately becomes apparent in the work of Stiegler, who can be considered a leftist thinker (Lemmens and Hui 2017, 38), but is at the same time one of today's most radical critics of infantilization. I will therefore now turn to his remarks on infantilization and maturity. ${ }^{5}$

\footnotetext{
4 The term 'infantilization' is also used in the history of childhood. However, rather than a condemnation of childish characteristics, it signifies the historical separation of childhood and adulthood: "The term infantilisation refers to the increasing length of the infantile phase and, inevitably related to this increase, an increasing distance between the infantile and the adult worlds" (Koops 2011, 3; see also Koops 2016). I use the term as it is used in cultural criticism rather than in the history of childhood.

5 At the time of finishing this article, Stiegler passed away. I believe we have lost one of today's most important and original philosophers.
} 
Since Stiegler is explicitly inspired by Kant's essay on Enlightenment, ${ }^{6}$ I will first present some of Kant's main remarks. As is well-known, Kant defined Enlightenment as "the human being's emergence from his self-incurred minority."7 He adds: "Minority is the inability to make use of one's own understanding without direction from another. This minority is self-incurred when its cause lies not in lack of understanding but in lack of resolution and courage to use it without direction from another" (Kant 1996, 17). This self-incurred minority must be distinguished from a natural minority intrinsic to each human being: "It is because of laziness and cowardice that so great a part of humankind, after nature has long since emancipated them from other people's direction (naturaliter maiorennes), nevertheless gladly remains minors for life ..." (Kant 1996, 17, my emphasis). Kant also notes this distinction in his Doctrine of Law, where he explicates natural minority as childhood (Brandt 2018, 151).

Kant thus argues that the human being does not necessarily go from immaturity to maturity. Immaturity can remain, although it does change from a natural to a self-incurred immaturity as the human being ages. The transition from immaturity to maturity therefore requires more than a natural process. Kant summarizes this in the famous first sentence of his Lectures on pedagogy: "The human being is the only creature that must be educated" (Kant 2007, 437). However, is Kant only writing of educating the human being from a child to an adult? Is Enlightenment not mostly a societal development, that is the upbringing of society rather than of individuals? Indeed, it is important to note the reciprocity between individual and societal development here. Enlightenment concerns both a society and the individuals living in it.

According to Kant then, the human being begins in an immature state, in a state of minority. The proper end of the human being is to become mature, but this transition is not natural. The state of immaturity can be overcome in maturity, but it can also continue in a new form, that is as self-incurred immaturity.

How does Stiegler appropriate Kant's essay? Stiegler follows Kant in understanding responsibility as the defining trait of maturity (Stiegler 2010, 3). Responsibility immediately refers to domains beyond the individual. The adult's responsibility is precisely to take care of the generations, to ensure that they can also leave their minority behind.

Stiegler also emphasizes Kant's remarks on the public use of reason. Contrary to the private use of reason, which is always in view of a certain end prescribed by something outside of reason such as the tasks of a law enforcer, the public use of reason is using reason for the sake of human freedom as such. Learning how to publicly use reason therefore requires an education that is not just aimed at producing law-abiding workers, but that trains the new generation in critical thinking as well. By using reason publicly, the human being presents him-/herself as a "scholar before the literate world", that is before a public capable of reading and writing (Kant, in: Stiegler 2010, 20). Therefore, "majority [maturity, DK] is a critical faculty presupposing the ability to read and write ..." (Stiegler 2010, 20). The education of the minor's mind requires reading and writing.

\footnotetext{
${ }^{6}$ In almost all of his works on contemporary culture, Stiegler refers to Kant's essay. This goes from a single reference in for example L'immense regression to a continuous commentary and inspiration in Taking Care.

7 "Minority" translates the German "Unmundigkeit." I will use this term because it fits best with the term Stiegler uses to translate it, namely minorité. However, this translation misses the crucial connotation of not being able to speak (for oneself). For the difficulties of translating Unmundigkeit and alternative translations, see the translator's remarks in Foucault (2010).
} 
However, reading is not necessarily the remedy for the mind's initial minority. As Kant writes: "If I have a book to serve as my understanding, a pastor to serve as my conscience, a physician to determine my diet for me, I need not exert myself at all" (in: Stiegler 2010, 21 ). Reading books is necessary to be able to make public use of reason, yet reading books can also lead the human being to stop reasoning altogether, since the book has already done this for him/her. Stiegler explains: "Kant's issue here is the mind's pharmacology, and maturity as the pharmaka's proper end ..." $(2010,21) .^{8}$

The notion of pharmakon plays an important role in Stiegler's thought. This ancient Greek word translates to both remedy and poison. One of Stiegler's main theses throughout his works is that the human being is characterized by an original lack which must be supplemented with exterior technology in order to become human (Stiegler 1998). However, this supplemental technology can also foreclose this becoming-human. This is why Stiegler refers to these technologies as pharmaka. In his reading of Kant, the book reveals itself as such a pharmakon, potentially remedy and poison. Maturity is the result when the book acts as a remedy of the mind's minority, while infantilization or adult immaturity is the result of a poisoning of the mind, which occurs when the book takes over the role of the understanding rather than being a necessary aspect of critical thinking.

However, Stiegler makes clear that the result of applying the pharmakon to the mind is not pure coincidence. It needs to be applied in a mind with the proper disposition in order to reach its proper end: "Aufklärung, adulthood ... requires the courage and the will to know" (Stiegler 2010, 20). Opposed to this is "our tendency toward the laziness and cowardice characterizing adult minority..." $(2010,20)$. It is therefore not enough to provide children with books to turn them into critical thinkers. In order to ensure the development towards adulthood, the tendency towards laziness and cowardice must be battled. However, as Kant already recognized, this tendency is being put to use and strengthened by malevolent guardians (Kant 1996, 17). We can think here of a teacher who teaches children to memorize the textbook, rather than enticing wonder and using the textbook as departure for questions and thought. The textbook can be considered a pharmakon, as it can be put to use both in a stupefying and an educational way. This example also shows that teachers can act as malevolent guardians, namely when they foreclose the critical possibilities of the textbook in their classes.

With these remarks and the basic relations between maturity and immaturity in place, I will now continue by emphasizing two points where Stiegler differs from Kant. Since Stiegler consistently focuses on the interrelation between the human and technology, the difference is mainly constituted by the difference in technology between Kant's age and our own. Stiegler thus appropriates Kant's essay on Enlightenment, yet also actualizes its arguments and appeal for our times. I will elaborate on this below.

\section{Stiegler's Critique of Infantilization}

Stiegler begins his most extensive work on infantilization-Taking Care of Youth and the Generations-almost immediately with the central claim of his critique: "undermining the difference between minors and adults is at the very heart of contemporary consumer

\footnotetext{
${ }^{8}$ I will return to this remark below, where I question Stiegler's ability to distinguish a "proper end" for the mind in his pharmacological framework.
} 
culture, which systematically defines consumers - minors and adults alike-as being fundamentally, structurally irresponsible" $(2010,2)$. Specifically, children are targeted as if they already are adult consumers, while adults are minoritized: "the becoming-prematurely-adult of children is the mirror image of the protracted retardation of their older siblings' and parents' minoritization" $(2010,41)$. It is this context of widespread self-incurred immaturity which inspires Stiegler's renewed appeal for Enlightenment.

As a prime example of infantilization, Stiegler mentions the TV-channel $Y$ which targets young audiences and ridicules adults. The marketeers themselves do not see this as infantilizing, but rather as the opposite: as "kid empowerment" (Barber 2007). But as Barber observes, this empowerment does not consist of responsibility, but only of the child's ability to consume what it 'wants,' or properly speaking, to consume what marketeers push toward. This new group of consumers, children, moreover has the advantage of immediately wanting a fulfillment of its 'needs.' The inability to postpone satisfaction of their desires becomes the norm for adult consumers as well (Stiegler 2010, 12-3). Therefore, Barber (2007, 32) writes: "for consumer capitalism to prevail you must make kids consumers or make consumers kids. That is to say, smarten up the kids- 'empower' them as spenders; and dumb down the grown-ups, disempower them as citizens."

This development has already infiltrated the discourses on education as well. The student is positioned more and more as a consumer, while the educator takes on the position of supplying the 'goods' that the consumer wants-or at least, thinks he or she wants (Biesta 2006).

Stiegler asserts that the blurring of the difference between children and adults is already taking place. The result of the blurred difference is not widespread maturity, but rather widespread infantilization. Stiegler views this as a potentially irreversible development, because - as we have seen above - maturity is required for maturing the minors of the generations to come. A total infantilization would therefore foreclose maturity for good. The immature can no longer be Enlightened.

Although Stiegler thus incorporates Kant's basic structure of maturity and immaturity, he also actualizes Kant's essay on two main points: first, the identification of the current status of the mind's pharmakon which used to be the book and second, the identification of the current malevolent guardians strengthening the mind's tendency towards laziness and cowardice.

We have already seen that for Stiegler, following Kant, reading and writing are crucial for maturity, understood as being able to make public use of reason. The question is whether the book still occupies the same place in the development of maturity. On first sight, the problem seems to have shifted. The question is not whether the book is used to strengthen one's own use of reason or to foreclose it, but rather whether the book can still be considered a pharmakon of the mind at all. Mark Fisher, in his excellent book Capitalist Realism, reports on his experiences as a teacher:

Ask students to read for more than a couple of sentences and many ... will protest that they can't do it. The most frequent complaint that the teachers hear is that it's boring. It is not so much the content of the written material that is at issue here; it is the act of reading itself that is deemed to be 'boring' (Fisher 2009, 23).

Other technologies are taking the place of the book and the written word in the mind's pharmacology. The mind's pharmacological organization now contains smartphones. Fisher $(2009,24)$ continues: "To be bored simply means to be removed from the communicative sensation-stimulus matrix of texting, YouTube and fast food; to be denied, for a moment, the constant flow of sugary gratification on demand." Can these other 
technologies supplement the mind's initial lack as good as the book can? Or does this change in technology lead to a change in the mind as well? Stiegler approaches this question by means of Katherine Hayles's notion of attention.

Hayles distinguishes deep attention from hyper attention. Deep attention is "characterized by concentrating on a single object for long periods ... ignoring outside stimuli while so engaged, preferring a single information stream, and having a high tolerance for long focus times" (Hayles 2007, 187). Hyper attention, on the other hand, is "characterized by switching focus rapidly among different tasks, preferring multiple information streams, seeking a high level of stimulation, and having a low tolerance for boredom" (ibid.). For Stiegler, the problem is that "only deep attention ... can lead to maturity" $(2010,77)$.

If the current state of technology rather trains hyper attention, the development towards maturity is indeed in danger. The new technologies cannot replace the older technologies (of the book for example) without replacing the mind's structure as well. Stiegler argues that this is reflected in, amongst other things, the rise of attention disorders.

Before continuing my argument, I shortly pause to consider some criticisms of Stiegler's bleak outlook. Gratton (2010) and Lewin (2016) have expressed doubts about Stiegler's pessimism. They point amongst other things to the increase of world-wide literacy and to Stiegler's one-sided view of attention disorders. Although my main focus is on Stiegler's notion of infantilization, I want to defend Stiegler in his pessimism. Especially Manfred Spitzer (2017) has shown, by referencing a staggering number of empirical investigations, that contemporary uses of technology and (social) media do change the way humans think and grow up. This shows itself in increased rates of stress and anxiety, decreased capacity for focused attention and correlations between smartphone use in class and exam rates. Stiegler's concerns can therefore be based on empirical research as well. However, he also adds important aspects to enrich these techno-pessimist claims.

First, since technology is intrinsically bound up with being human, we have to maintain the pharmacological rather than purely destructive character of technology. And second, Stiegler sees that the problem is not just technological, but political as well. This means that the malevolent guardians that Kant wrote about still exist, yet in a new appearance. Stiegler writes: "To reinvent maturity is to struggle against the psychopower of new 'guardians' who misuse these pharmaka and for whom new 'subjects' ... are consumers" $(2010,51)$.

The new 'guardians' are the industries that use all kinds of marketing ploys to push people into following their immediate drives rather than working on long-term desires. Like Barber (2007), Stiegler asserts that some people are indeed guilty of deliberately accelerating infantilization: "Service industries that utilize psychopower no longer sell anything to a population that thus no longer needs to pay anything: people, having abdicated their majority without being conscious of it, 'give themselves' to these industries, or rather, the industries capture them as 'available brain time' ..." $(2010,38)$. The human being's inherent tendency towards laziness and cowardice is put to use and strengthened, while the paths towards critical maturity are deliberately cut off.

So far I have discussed Stiegler's main remarks on maturity and infantilization, or in Kantian terms "self-incurred immaturity." It is clear that Stiegler remains very close to Kant's remarks. He explicitly phrases the dangers of contemporary consumer culture in Kant's terms of maturity, minority and "Enlightenment".

However, while Kant terms the adult immaturity "self-incurred," Stiegler is more explicit about the role of the 'guardians' in cultivating this immaturity. Although humans must fight against their inherent tendency towards cowardice and laziness, Stiegler suggests that the resulting immaturity is less the effect of self-incurrence than of the 
self-strengthening result of contemporary capitalism. And since marketing companies target increasingly younger audiences (for example by means of apps like TikTok, Snapchat and Instagram), the possibilities of developing a critical mature self become less, while the chances to grow up into an infantilized adult increase.

Let us summarize our findings thus far. Like Kant, Stiegler understands minority as a lack of maturity. The notion of infantilization or minoritization is therefore immediately negative. The consequence of this is that the only available strategy to counter the dangers of infantilization is to call for a new maturity. This is then also the path Stiegler takes in his book Taking Care, inspired by the eighteenth-century maturity lauded by Kant.

\section{Stiegler's Positive Notion of Childhood}

Still in Taking Care however, it becomes clear that this negative understanding of childhood and infantilization is only part of the story. A first question arises due to Stiegler's assertion that “... we can never become completely mature ...” $(2010,87)$. This is an interesting statement in the context of his call for maturity, because it means that humankind seems to be marked by an essential possibility of infantilization. This is more in line with Stiegler's pharmacological approach to the human being. Since maturity is only arrived at by means of technology, and since technology is considered a pharmacological supplement to the human being's original lack of essence, every maturity is necessarily only partial and precarious. The lack of a human essence also forecloses in advance the possibility of distinguishing between a proper mature end of humankind and an improper infantile end. At best, we can agree on more or less desirable developments of human being and society. ${ }^{9}$

The binary opposition between negative improper immaturity and positive proper maturity becomes more complicated. Stiegler develops this in other works, and I will therefore now read these in order to elaborate on this. Specifically, I will read some remarks from an interview on childhood (Kouppanou 2016) and from his book What Makes Life Worth Living (2013b).

A statement in the interview on childhood serves as my starting point. Here Stiegler says that "childhood is the age of play" (Kouppanou 2016, 244). This statement in itself does not yet reveal whether the extension of play into maturity can be good as well, so I will develop this remark further. Stiegler refers to the objects of play: "in the case of childhood, to play is to play with a transitional object." The main inspiration here is Winnicott's theory of the transitional object as presented in Playing and Reality.

Stiegler affirms Winnicott's basic idea that the transitional object mediates the separation of parent and child. Through the 'real' object, which can be a toy but also a word, a space is opened which is not solely external reality yet also not internal reality. Rather, it is something which gradually installs this difference in the first place. This reveals that for Stiegler, the development of humankind in general and the development of an individual human being follow parallel paths (Stiegler 2013b, 20). Just as humankind lacks an origin and only becomes human by supplementing this lack with different technologies, so the

\footnotetext{
9 I therefore agree with Van der Heiden's critique when he writes that "for Derrida, the notion of pharmakon was introduced to problematize the distinction between good and bad writing, whereas Stiegler uses the same notion to distinguish between good and bad technics, disorienting and orienting technologies, threatening and saving technics" (van der Heiden 2016, 26).
} 
individual human being has a "default of interiority" and is only 'humanized' by means of the supplemental transitional object.

However, the space opened up through the transitional object cannot then be reduced either to internal reality or external reality. Stiegler understands this space-conceptualized by Winnicott as "potential space"-as the "plane of consistencies" (see Kouppanou 2016). This is the domain of non-existent objects, or in other words: ideal objects. The transitional object thus introduces the infant to the domain where consciousness and reason can develop, but also to the endless workings of desire (which aims at non-existent infinite objects).

In the life of the child, any object can serve as transitional object. Winnicott reminds us that the kind of object is totally contingent, because it is the use of the object which makes it a transitional object (2005, xvi-xvii). Stiegler however specifies that the object "is always already a technical thing" (Kouppanou 2016, 244). By focusing on the object in the context of the question of childhood, Stiegler turns away from the status of the infant that confronts this object in the first place (van der Heiden 2016; Kouppanou 2020). I will consider the consequences of this below, but first I will analyze Stiegler's view of the infant's play in more detail.

The most relevant for the notion of infantilization is Stiegler's striking affirmation of the continuity between the infant's play with the transitional object and the idealities of consciousness: "He [Winnicott, DK] says in Play and Game ${ }^{10}$ that the scientific, artistic work is a continuation of the life of the child" (Kouppanou 2016, 245). Here Stiegler already provides, by way of Winnicott's thesis, an opening to a different notion of infantilization which is not necessarily negative.

Winnicott's thesis reveals a remainder of childhood that is crucial to the life of the mind, rather than opposed to it. Like Stiegler who stated that one can never become fully mature, Winnicott explicitly asserts that play is not limited to childhood. He continuously stresses the importance of play and creativity for adult life as well. This continuity of creativity is affirmed in a striking example:

It [the creative impulse, DK] is present as much in the moment-by-moment living of a backward child who is enjoying breathing as it is in the inspiration of an architect who suddenly knows what it is that he wishes to construct, and who is thinking in terms of material that can actually be used so that his creative impulse may take form and shape, and the world may witness (Winnicott 2005, 92-93).

But Winnicott sums it up in clearer words elsewhere: "The essential feature of my communication is this, that playing is an experience, always a creative experience, and it is an experience in the space-time continuum, a basic form of living" $(2005,67)$.

How does Stiegler take this understanding of play into account? Again, we can detect a difference in emphasis between his remarks in Taking Care and in his other works. In the first, the focus is on the adult's responsibility to play with the child. Stiegler writes "to play with a child is to take care of the child ..." $(2010,14)$. In What Makes Life Worth Living, he conceptualizes play first and foremost as the act of the child playing with transitional objects, which as Winnicott wrote, extends into the play of the artist or the scientist with their material. Are these therefore two different kinds of playing? Or can these two different remarks be combined?

\footnotetext{
10 The reference seems to be to Winnicott's book Playing and Reality (see the quote in Stiegler 2013b, 47). I have not been able to find a text by Winnicott with the title Play and Game.
} 
Stiegler implies in Taking Care that the different kinds of emphasis can be synthesized. The adult's responsibility to play with the child entails for both child and adult a kind of opening up to phantasy and creativity. Although one could argue that the adult can halfheartedly join the child just to allow the child to be able to play, Stiegler suggests that this is not the kind of play he aims at. When Stiegler writes about play, he means authentic playing, for both child and adult. Now what is interesting for the notion of infantilization is that Winnicott asserted, and Stiegler follows him in this, that the age of play indeed continues throughout maturity as well. This means that play is an activity which allows one to enter into a zone which is neither solely mature nor solely 'childish.' I will investigate this in more detail to draw out the consequences for a notion of infantilization which is not solely negative.

\section{Infantilization as Risk}

I have shown above how Stiegler's appropriation of Winnicott's theory already reveals a sense of infantilization that is not in opposition with the critical project of Taking Care. While Stiegler condemned remainders of childhood as regression and immaturity in Taking Care, he acknowledges the crucial role of these remainders in the works of artists, scientists and philosophers in What Makes Life Worth Living and the interview on childhood and education. Therefore, I believe that Stiegler's project can be strengthened by constructing a notion of infantilization that incorporates both these possibilities, rather than only the negative sense that is operative in Taking Care. This is not just a theoretical improvement, since it is more in line with the pharmacological view of human nature, but it also has consequences for Stiegler's view on the practice of education.

As we have already seen in the first section of this article, Stiegler understands maturity as characterized primarily by responsibility. This responsibility is intrinsically connected to education, as Stiegler writes on the first page of Taking Care that responsibility is "before all else, the adult responsibility of taking care of the young..." $(2010,1)$. In the previous section, we have seen that this taking care involves play. This does not mean that the mature should allow children to play, without engaging in play themselves. Rather, taking up mature responsibility is precisely engaging in play with the younger generation (Stiegler $2010,8)$. This means that a maturity that excludes "the age of play" - that is, childhoodfrom itself is not mature at all. In sum, maturity entails a constitutive risk: for it to be maturity, it must open itself to its remainders of childhood. It must allow for play and surrender to the creative impulse it can awaken. Winnicott already knew this: "It is in playing and only in playing that the individual child or adult is able to be creative and to use the whole personality, and it is only in being creative that the individual discovers the self" (2005, 73). However, and this is Stiegler's important contribution, these remainders of childhood can just as well lead to infantilization and stop the human being from becoming mature. In his remarks on education in Taking Care, Stiegler unfortunately only thoroughly considers the latter option.

This becomes apparent when he discusses the handing down of tradition to new generations. With a play on words, we can note that Stiegler's view lacks sufficient play (both in the sense of playing and in the sense of leeway or elbow room). This is argued forcefully by Gratton (2010), who writes in his review of Taking Care:

it is more than striking that Stiegler has not paused before arguing for a renewed

European culture while generously citing Jules Ferry regarding civilizational 'matu- 
rity' and 'social primary identification' ... Ferry's legacy was not simply secular public schools, but also an impassioned imperialism guided by his claim that it was the French 'duty to civilize the inferior races' ... Privileging 'systems of care,' a renewed Europe, and a 'battle for intelligence' as a 'process' of 'unification,' which, he writes, 'in Jules Ferry's time [was] called "the nation,"' while discussing the masses in the same coded language of nineteenth century racialists ('lazy,' non-thinking, immature, etc.) is ominous.

I fully agree with Gratton that Stiegler hereby undermines his very project of taking care of new generations. He continues: "isn't there something strange about a book that talks about 'caring for the youth' that robs those very youth of any autonomy, of any thought, as Stiegler defines those terms?" Indeed, it seems that Stiegler-although aware of the risk inherent in the education of new generations-ends up claiming the sole right of critically engaging with tradition, thereby depriving the new generations of it as a consequence. However, our expansion of the notion of infantilization allows for a correction of Stiegler's conservative views.

As Stiegler has shown in his other works, the fast and radical technological changes of the last decades confront contemporary society with a pharmacological event like none before. This is why he calls for the invention of new ways of living $(2010,48,89)$. I believe this is first and foremost a call for creativity, which, as Winnicott asserted, originates in and continues the infant's play with the transitional object. In order then to take care of the new generations as Stiegler calls for, it is necessary to acknowledge first the remainders of childhood in maturity and second, the new generation's ability to creatively engage with tradition.

Rather than calling for a new maturity, the ambivalence of infantilization should be acknowledged. Stiegler's concession that one can never become fully mature, combined with his account of childhood as the age of play and crucial component of creativity, should lead to a different comportment towards the relation between adulthood and childhood. The end of humankind can no longer simply be maturity, but should rather be a specific composition of childhood and maturity. In Taking Care, Stiegler only sees a composition that destroys maturity altogether, but this should be complemented with his more implicit views on the life and works of artists and scientists, which show that a positive composition is possible as well. What these two possibilities show is that the continuation of childhood within maturity entails a fundamental risk. It is here that the role of care must be discerned, rather than in a repression of the remainders of childhood altogether.

\section{Conclusion}

The aim of this paper was to critically analyze Stiegler's diagnosis of contemporary culture as infantilized. We have seen that Stiegler identifies important concerns for education: the intrusion of economic discourses and capitalist actors in educational environments, and the essential rather than accidental consequences brought about by technological developments. However, summarizing this critique in terms of infantilization leads Stiegler to a one-sided call for more maturity. In the vein of Stiegler's pharmacological approach to human being, I have argued that infantilization itself is ambivalent.

Stiegler constructs his notion of infantilization by means of an appropriation of elements of Kant's essay on Enlightenment, which contains a negative understanding of immaturity combined with a positive evaluation of maturity. However, this negative 
understanding of childhood and infantilization is only part of the picture. In other works, Stiegler himself affirms a more positive understanding of childhood. Specifically, he terms childhood "the age of play" and asserts that it is crucial to the life of the mind to extend this childhood into maturity. Stiegler concedes that maturity can never be fully obtained. I have identified this as a necessary effect of his pharmacological understanding of humankind. The possibility of infantilization cannot be completely warded off, because it is characteristic of humankind's default of origin. Maturity can never fully take up the place of childhood. I have argued that Stiegler's project can be strengthened by synthesizing this other understanding of childhood and of infantilization with the negative concept operative throughout Taking Care.

To correct Stiegler's account of childhood and maturity, I proposed to understand infantilization as ambivalent: it is required for critical maturity, yet it can also foreclose it (and only this last possibility is thoroughly explored by Stiegler). As Stiegler's pharmacological approach teaches us, this risk is unavoidable. The benefit of this new account is that it upholds Stiegler's insights into the fundamental role of technology in being human, but corrects his one-sided views on education.

We can state that education is indeed crucial, yet in a different form than envisaged by Stiegler himself. Rather than placing youth in the contradiction of being at the same time unable yet required to take their part in the invention of new ways of living, education should allow children to experience an ability to creatively engage with tradition and take care of it. The risk that this entails is not something to deplore, as it is essential to education and being human. The question rather becomes how to properly take care of this risk.

In conclusion, this paper has resulted in an immanent critique of Stiegler's notion of infantilization and an understanding of infantilization as fundamentally ambivalent rather than solely negative. However, Stiegler's warning in Taking Care still holds. Humankind's essential possibility of infantilization requires care and education in view of the danger that infantilization is actualized not in view of critical maturity, but rather as a destruction of the life of the mind and a victory of consumerist capitalism.

Further research is therefore needed to understand human being's essential possibility of infantilization. Remainders of childhood seem at the same time the greatest danger for critical maturity, yet also required for it. To understand this, it is necessary to ask in what sense(s) childhood remains in maturity. Stiegler's reference to playing is only one aspect of this. Van der Heiden (2016) has pointed to Stiegler's "default of origin" as a possible direction for further research. Rather than solely a default, Van der Heiden proposes - with reference to Jean-François Lyotard's work on infancy-to understand this lack of origin as a productive potentiality. This also changes the way in which the default of origin remains in maturity. Although this is already a fertile start, I believe a systematic account of subjectivity in view of what we can perhaps term 'transcendental infancy' is still to be constructed.

Funding Not applicable.

Availability of Data and Material Not applicable.

Code Availability Not applicable. 


\section{Compliance with Ethical Standards}

Conflict of interest The author declares that there is no conflicts of interest or competing interests.

Open Access This article is licensed under a Creative Commons Attribution 4.0 International License, which permits use, sharing, adaptation, distribution and reproduction in any medium or format, as long as you give appropriate credit to the original author(s) and the source, provide a link to the Creative Commons licence, and indicate if changes were made. The images or other third party material in this article are included in the article's Creative Commons licence, unless indicated otherwise in a credit line to the material. If material is not included in the article's Creative Commons licence and your intended use is not permitted by statutory regulation or exceeds the permitted use, you will need to obtain permission directly from the copyright holder. To view a copy of this licence, visit http://creativecommons.org/licenses/by/4.0/.

\section{References}

Badiou, Alain. 2017. The True Life, trans. Susan Spitzer. Cambridge: Polity.

Barber, Benjamin. 2007. Consumed. New York: W. W. Norton.

Biesta, Gert. 2006. Beyond Learning. Boulder: Paradigm.

Bradley, Joff. 2020. Negen-u-topic Becoming: On the Reinvention of Youth. Educational Philosophy and Theory 52 (4): 443-454.

Bradley, Joff, and David Kennedy. 2020. Stiegler as Philosopher of Education. Educational Philosophy and Theory 52 (4): 332-336.

Brandt, Reinhard. 2018. Was ist Aufklärung? Beobachtungen zur Kantischen Antwort. Kant-Studien 109 (1): 147-169.

Dasberg, Lea. 1975. Grootbrengen door kleinhouden. Meppel: Boom.

Dufour, Dany-Robert. 2008. The Art of Shrinking Heads, trans. David Macey. Cambridge: Polity.

Fisher, Mark. 2009. Capitalist Realism. London: Zero.

Forrest, Kristy. 2020. The Problem of Now: Bernard Stiegler and the Student as Consumer. Educational Philosophy and Theory 52 (4): 337-347.

Foucault, Michel. 2010. The Government of Self and Others, ed. Frédéric Gros, François Ewald, Alessandro Fontana and Arnold I. Davidson, trans. Graham Burchell. London: Palgrave Macmillan.

Furedi, Frank. 2009. Wasted: Why Education Isn't Educating. London: Continuum.

Gottschalk, Simon. 2018. The Infantilization of Western Culture. The Conversation. https://theconversation .com/the-infantilization-of-western-culture-99556.

Gratton, Peter. 2010. Taking Care of Youth and the Generations. Notre Dame Philosophical Review. https:// ndpr.nd.edu/news/taking-care-of-youth-and-the-generations/.

Guattari, Félix. 2009. So What. In Soft Subversions, ed. Sylvère Lotringer, 64-80. Los Angeles: Semiotext(e).

Hayles, Katherine. 2007. Hyper and Deep Attention: The Generational Divide in Cognitive Modes. Profession: 187-199.

Kant, Immanuel. 1996. An Answer to the Question: What is Enlightenment? In Practical Philosophy, ed. and trans. Mary J. Gregor, 11-22. Cambridge: Cambridge University Press.

Kant, Immanuel. 2007. Lectures on Pedagogy. In Anthropology, History, and Education, ed. Günter. Zöller and Robert B. Louden, 434-485. Cambridge: Cambridge University Press.

Koops, Willem. 2011. Childhood as a Mirror of Culture. Indo-Pacific Journal of Phenomenology 11 (2): 1-9.

Koops, Willem. 2016. Een beeld van een kind. Amsterdam: Boom.

Kouppanou, Anna. 2016. ‘...Einstein's Most Rational Dimension of Noetic Life and the Teddy Bear...': An Interview with Bernard Stiegler on Childhood, Education and the Digital. Studies in Philosophy and Education 35 (3): 241-249.

Kouppanou, Anna. 2020. What Is In a Child's Hand? Prosthesis in Bernard Stiegler: Some Implications For a Future Philosophy of Childhood. Educational Philosophy and Theory 52 (4): 433-442.

Lemmens, Pieter, and Yuk Hui. 2017. Reframing the Technosphere. Krisis 2: 26-41.

Levi-Strauss, Claude. 1946. La technique du bonheur. Esprit 127: 634-652.

Lewin, David. 2016. The Pharmakon of Educational Technology: The Disruptive Power of Attention in Education. Studies in Philosophy and Education 35 (3): 251-265.

Pfeiffer, Ilja Leonard. 2018. Grand Hotel Europa. Amsterdam: Arbeiderspers.

Plato. 1997. Complete Works, ed. John M. Cooper and D. S. Hutchinson. Indianapolis: Hackett.

Postman, Neil. 1982. The Disappearance of Childhood. New York: Delacorte.

Rowland, Ann Wierda. 2012. Romanticism and Childhood. Cambridge: Cambridge University Press.

Spitzer, Manfred. 2017. Cyberkrank! München: Droemer. 
Stiegler, Bernard. 1998. Technics and Time 1: The Fault of Epimetheus, trans. Richard Beardsworth and George Collins. Stanford: Stanford University Press.

Stiegler, Bernard. 2010. Taking Care of Youth and the Generations, trans. Stephen Barker. Stanford: Stanford University Press.

Stiegler, Bernard. 2013a. Die Aufklärung in the Age of Philosophical Engineering. In Digital Enlightenment Yearbook, ed. Mireille Hildebrandt, Kieron O'Hara, and Michael Waidner, 29-39. Clifton: IOS Press.

Stiegler, Bernard. 2013b. What Makes Life Worth Living, trans. Daniel Ross. Cambridge: Polity.

Stiegler, Bernard. 2015. States of Shock, trans. Daniel Ross. Cambridge: Polity.

Stiegler, Bernard. 2018. Qu'appele-t-on panser? 1: L'immense regression. Paris: Les Liens Qui Libèrent.

van der Heiden, Gert-Jan. 2016. Technology and Childhood. International Yearbook for Hermeneutics 15: 16-34.

Winnicott, David. 2005. Playing and Reality. London: Routledge.

Publisher's Note Springer Nature remains neutral with regard to jurisdictional claims in published maps and institutional affiliations. 